\title{
Clinicopathological significance of HSP27 in gastric cancer: a meta-analysis
}

This article was published in the following Dove Press journal:

OncoTargets and Therapy

13 September 2017

Number of times this article has been viewed

Hua Ge

Xueyan $\mathrm{He}$

Lingfei Guo

Xianzhi Yang

Department of Gastrointestinal Surgery, The First People's Hospital of Zunyi, Zunyi Medical University, Zunyi, Guizhou, People's Republic of China
Correspondence: Hua Ge

Department of Gastrointestinal Surgery,

The First People's Hospital of Zunyi,

Zunyi Medical University, No 98

Fenghuang Street, Huichuan, Zunyi

563000, People's Republic of China

Tel +86 I8685237II9

Email zyyyhuage@126.com
Background: Many studies have provided increasing evidence to demonstrate that HSP27 has been involved in the development of gastric cancer; however, they all include few patients and the results remain controversial. Hence, we conducted a meta-analysis to evaluate correlations between HSP27 and the clinicopathological characteristics of gastric cancer.

Methods: An electronic search for relevant articles was conducted in PubMed, Cochrane Library, Web of Science, EMBASE database, Chinese CNKI, and Wan Fang. Data on the relationship between HSP27 expression and lymph node metastasis, serosal invasion, gender, tumor size, differentiation, and TNM stage were extracted. Pooled odds ratios and 95\% confidence intervals were estimated by forest plot.

Results: The pooled analyses suggested that HSP27 expression was significantly associated with the incidence of gastric cancer. However, HSP27 expression had no significant relationship with lymph node metastasis, serosal invasion, gender, tumor size, differentiation, and TNM stage.

Conclusion: Our meta-analysis demonstrated that HSP27 may play vital roles in tumorigenesis and deterioration of gastric cancer. However, further high-quality studies are needed to provide more reliable evidence.

Keywords: heat shock protein 27, gastric cancer, meta-analysis

\section{Introduction}

Gastric cancer is one of the leading causes of malignancy-related death around the world. It has been reported that gastric cancer is the fifth most common cancer worldwide, and the fatality rate is $75 \%$, accounting for $8.8 \%$ of the total deaths due to cancer. ${ }^{1}$ Although there is a trend of decreasing mortality rates of stomach cancer attributed to cancer screening, reduced prevalence of risk factors, and improved treatments, the prognosis of gastric patients remains poor. ${ }^{2,3}$ Heat shock proteins (HSPs) are ubiquitous, highly conserved proteins, which are induced by heat shock and environmental and physiopathological stresses. ${ }^{4}$ Recent evidence suggested that HSPs may have a close relationship with gastric neoplasia. ${ }^{5-7}$ Besides, it has been reported that the expression of HSPs also correlated with clinical characteristics in gastric cancer. ${ }^{8-10}$

HSP27 is a member of the small HSPs and is a major molecular chaperone with a protective effect on cells, which has the function of regulating normal cell physiology and the cellular stress response. ${ }^{11-13}$ HSP27 is expressed at low levels in normal cells. ${ }^{14}$ However, its aberrant expression has been reported in various malignant tumors, such as gastric, ${ }^{15}$ colon, ${ }^{16}$ hepatocellular, ${ }^{17}$ lung, ${ }^{18}$ cervical, ${ }^{19}$ ovarian, ${ }^{20}$ and breast cancer. ${ }^{21}$ Moreover, these reports have also indicated the oncogenic potential of HSP27 and its utility as a cancer biomarker. A previous meta-analysis reported that overexpression of HSP27 was closely related to clinicopathological features, including the differentiation 
degree, lymphatic metastasis, clinical stage, squamous cell carcinoma, and tumor size in non-small-cell lung cancer. ${ }^{22}$ Although some studies have explored the role of HSP27 overexpression in stomach cancer, ${ }^{8,15,23}$ there is still no summary evidence for the association between HSP27 and gastric cancer. Therefore, we conducted this meta-analysis to explore the relationship between the HSP27 expression and clinicopathological characteristics of gastric cancer patients.

\section{Methods}

\section{Identification and eligibility of relevant studies}

We searched PubMed, Cochrane Library, Web of Science, EMBASE database, Chinese CNKI, and Wan Fang to identify studies that assessed the clinicopathological factors and prognostic value of HSP27 expression in gastric cancer patients using immunohistochemistry (IHC). The search ended in July 1, 2017. Search words were "heat shock protein 27”, “HSP27”, “gastric cancer”, "'gastric carcinoma”, and "stomach neoplasm". The reference list of included studies was also checked to find out other qualified studies.

Studies were included if the following criteria were met: 1) the study was published in English or Chinese with full text being available; 2) patients in studies were clearly diagnosed with gastric cancer; 3) the definition of HSP27-positive was tested by IHC method; 4) studies included were case-control studies that evaluated the correlation between HSP27 expression and clinicopathological features or prognosis in stomach cancer; 5) studies included at least one primary outcome of interest; and 6) letters, reviews, conference abstracts, and duplicated studies were excluded.

\section{Data extraction}

Two reviewers independently screened all literature to determine whether the relevant articles meet the included criteria. Extracted data including the first author's name, publication year, sample size, country, and clinicopathological parameters (expression, lymph node metastasis, serosal invasion, gender, tumor size, differentiation, and TNM stage). Disagreements were resolved by reextraction or third-party adjudication.

\section{Quality assessment}

The quality of each included studies was assessed by the Newcastle-Ottawa Scale (NOS) criteria, and we regarded studies with NOS score of $\geq 6$ as a good quality, while studies with NOS score $\leq 5$ were considered as poor quality.

\section{Statistical analysis}

STATA 12.0 was used for statistical calculations. Pooled odds ratios (ORs) with 95\% confidence intervals (CIs) were calculated to evaluate the association between positive HSP27 expression and clinicopathological features (lymph node metastasis [yes vs no], serosal invasion [yes vs no], gender [male vs female], tumor size [ $\leq 5 \mathrm{~cm}$ vs $>5 \mathrm{~cm}$ ], differentiation type [low vs high/moderate], TNM stage [I/II vs III/IV]), meanwhile the expression of HSP27 between cancer tissues and control tissues was also evaluated. The heterogeneity between the studies was evaluated by $I^{2}$ test. Fixed effects model was chosen when there was no significant heterogeneity $\left(I^{2}<50 \%\right.$, P-Het $\left.>0.1\right)$. If heterogeneity was significant, the random effects model would be used. Potential causes of statistical heterogeneity were explored by subgroup analysis. Publication bias was examined by the Begg's funnel plot test.

\section{Results Eligible studies}

As shown in Figure 1, we identified 538 relevant articles through combined manual and computerized retrieval from PubMed, Cochrane Library, Web of Science, EMBASE database, Chinese CNKI, and Wan Fang. Of these, 517 were excluded after reviewing the titles and abstracts because these articles were duplicated, non-HSP27-related, or did not involve testing of tumor tissues. A total of 21 studies were assessed by reading the full text, and then 12 studies were excluded due to insufficient information and/or lack of cut-off value of HSP27 expression. Finally, 9 eligible articles were included in this meta-analysis. ${ }^{15,24-31}$

The characteristics of the included studies are summarized in Table 1. These studies were published from 2002 to 2015 , and a total of 624 gastric cancer patients were enrolled. Sample sizes ranged from 34 to 118 patients. Four of these studies enrolled $\leq 60$ patients and 5 studies included $>60$ patients. Eight of these studies evaluated patients from China and one from Greece. All of these studies scored $\geq 6$ in methodological assessment, which implied they were of high quality.

\section{Meta-analysis}

In this meta-analysis, we assessed the correlation between HSP27 expression and clinicopathological features of gastric carcinoma. As shown in Table 2 and Figure 2, overexpression of HSP27 was associated with the incidence of gastric cancer $(\mathrm{OR}=4.73,95 \% \mathrm{CI}=2.22-10.05, P=0.000)$. However, our result showed that overexpression of HSP27 was 


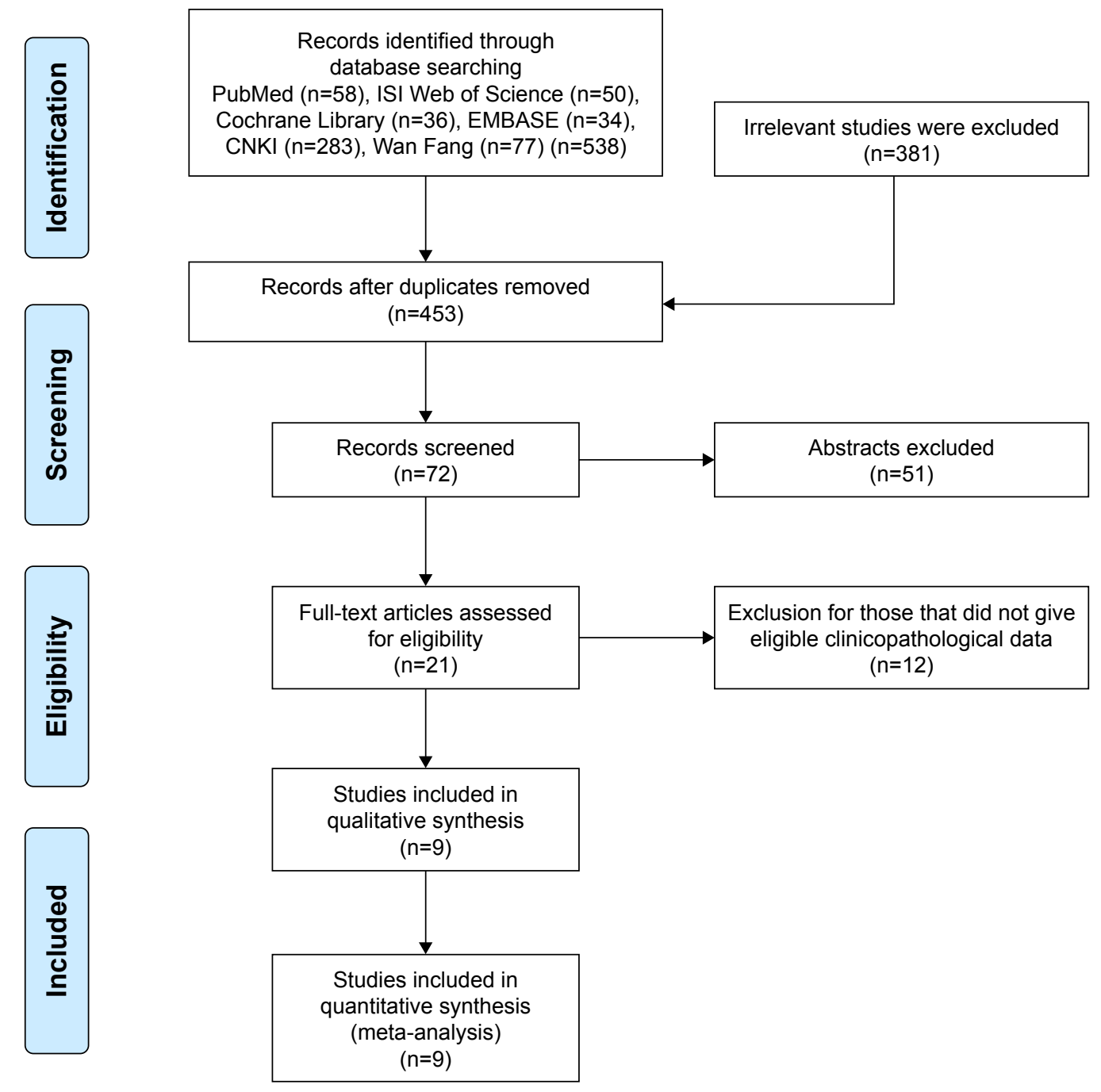

Figure I Flowchart of study selection.

not significantly associated with lymph node metastasis ( $\mathrm{OR}=1.32,95 \% \mathrm{CI}=0.64-2.72, P=0.453)$, serosal invasion $(\mathrm{OR}=1.31,95 \% \mathrm{CI}=0.81-2.12, P=0.267)$, gender $(\mathrm{OR}=0.73,95 \% \mathrm{CI}=0.50-1.08, P=0.120)$, tumor size (OR $=0.56,95 \% \mathrm{CI}=0.16-1.91, P=0.354)$, differentiation $(\mathrm{OR}=1.47,95 \% \mathrm{CI}=0.51-4.22, P=0.473)$, and TNM stage $(\mathrm{OR}=0.70,95 \% \mathrm{CI}=0.46-1.08, P=0.111)$.

\section{Publication bias and sensitivity analysis}

As shown in Figure 3A, Begg's test suggested that publication bias existed for expression $(P=0.048)$. However, as shown in Figure $3 \mathrm{~B}-\mathrm{G}$, there was no publication bias for lymph node metastasis $(P=0.902)$, serosal invasion $(P=1.000)$, gender $(P=1.000)$, tumor size $(P=0.296)$, differentiation $(P=0.806)$, and TNM stage $(P=0.462)$. Hence, the sensitivity analysis was conducted to evaluate whether individual studies influenced pooled OR, and the result indicated that no study substantially influenced pooled OR, which indicates that more studies need to be included for further research.

\section{Subgroup analysis}

Subgroup analysis was mainly performed on sample size to explore the potential sources of heterogeneity. As seen in Table 3, while in both subgroups divided by sample size, HSP27 expression was correlated to tumor incidence ( $\mathrm{n} \leq 60$ : $\mathrm{OR}=12.15,95 \% \mathrm{CI}=6.12-24.13, P=0.000 ; \mathrm{n}>60: \mathrm{OR}=2.51$, $95 \% \mathrm{CI}=1.05-6.01, P=0.039)$. However, the heterogeneity of HSP27 expression mainly existed in the bigger sample size subgroup $(\mathrm{n}>60)\left(I^{2}=88.2 \%\right)$. Sample size did not influence the relationship between HSP27 and lymph node metastasis and also tumor size, and there was great heterogeneity in subgroups (lymph node metastasis: $\mathrm{n} \leq 60$ : $I^{2}=79.2 \%$; 


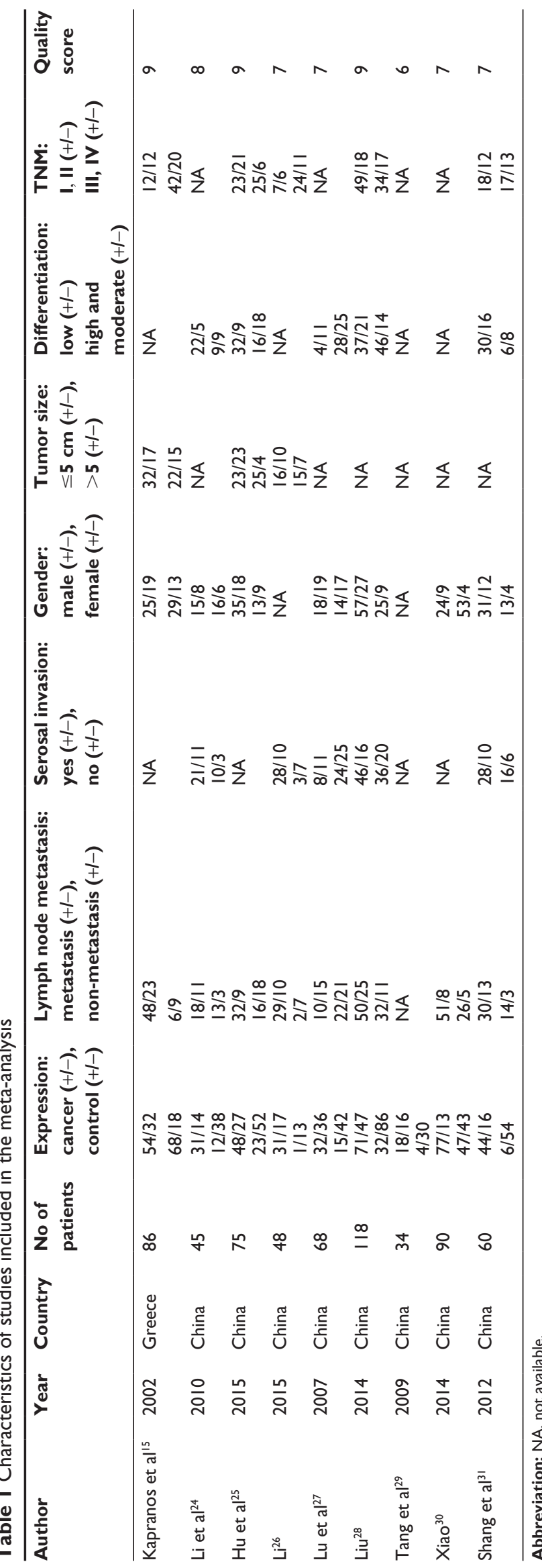

$\mathrm{n}>60: I^{2}=64.6 \%$; tumor size: $\mathrm{n}>60: I^{2}=86.8 \%$ ). When divided by sample size, the subgroup analysis showed that in small sample size group ( $\leq 60)$, upregulated HSP27 was associated with poor differentiation $(\mathrm{OR}=3.23,95 \%$ $\mathrm{CI}=1.31-7.96, P=0.011)$. While in bigger sample size group $(\mathrm{n}>60)$, there was no relationship between differentiation and HSP27 expression (OR $=0.90,95 \% \mathrm{CI}=0.21-3.91$, $P=0.892$ ). Additionally, the heterogeneity of HSP27 expression mainly existed in the bigger sample size subgroup (n $>60)\left(I^{2}=84.2 \%\right)$. With these results, the heterogeneity of HSP27 expression and differentiation was most likely caused by the sample size.

\section{Discussion}

HSPs have been reported to be overexpressed in a wide range of human tumors, the expression of HSPs was associated with tumor cell growth, differentiation, resistance to apoptosis, and poor prognosis..$^{32,33} \mathrm{HSP} 27$, an ATP-independent molecular chaperone, is a member of the small $\mathrm{HSPs},{ }^{34}$ and it has a protective effect on stress conditions, such as oxidative stress and chemical stress. ${ }^{13,35}$ Overexpression of HSP27 is associated with carcinogenesis, such as suppression of apoptosis, increased cytoprotection, and multidrug resistance ${ }^{14}$ Cytoplasmic HSP27 may bind to cytochrome c released from the mitochondria to the cytosol and prevents cytochrome-c-mediated caspase-dependent cell death. ${ }^{36}$ HSP27 also inhibits apoptosis by regulating other signaling pathways, including Fas receptor pathway, ${ }^{37}$ protein kinase AKT, ${ }^{38}$ signal transducer and activator of transcription- $3,{ }^{39}$ and the NF-kB signaling pathway. ${ }^{40}$ As for cancer therapy resistance, HSP27 can confer cytoprotection by repairing the damaged proteins and DNAs from cytotoxic drug with higher efficiency, protecting the microvasculature inside tumors. ${ }^{32}$

High levels of HSP27 can be found in multiple human malignancies, and the association of HSP27 with gastric cancer and clinicopathologic features has been explored for several years. However, the available data have not yet been fully analyzed. In this paper, we conducted a meta-analysis to investigate the association between HSP27 expression of stomach carcinoma patients and clinicopathologic features.

Combining the outcomes of 624 patients from 9 studies, our analysis revealed that positive HSP27 expression significantly correlated with the incidence of gastric cancer. In addition, statistically significant correlations were not observed between HSP27 expression and clinicopathological features including lymph node metastasis, serosal invasion, gender, tumor size, differentiation, and TNM stage. 
Table 2 HSP27 clinicopathological features for gastric carcinoma

\begin{tabular}{|c|c|c|c|c|c|c|c|}
\hline \multirow{2}{*}{$\begin{array}{l}\text { Clinicopathological } \\
\text { features }\end{array}$} & \multicolumn{7}{|l|}{ Heterogeneity } \\
\hline & No of studies & No of patients & Pooled OR $(95 \% \mathrm{Cl})$ & PHet & $I^{2}(\%)$ & $P$-value & Model used \\
\hline Expression & 9 & 624 & $4.73(2.22-10.05)$ & 0.000 & 86.5 & 0.000 & Random \\
\hline Lymph node metastasis & 8 & 590 & $1.32(0.64-2.72)$ & 0.003 & 67.1 & 0.453 & Random \\
\hline Serosal invasion & 5 & 339 & $1.31(0.8 \mathrm{I}-2.12)$ & 0.147 & 41.2 & 0.267 & Fixed \\
\hline Gender & 7 & 542 & $0.73(0.50-1.08)$ & 0.377 & 6.7 & 0.120 & Fixed \\
\hline Tumor size & 3 & 209 & $0.56(0.16-1.91)$ & 0.022 & 73.7 & 0.354 & Random \\
\hline Differentiation & 5 & 366 & $\mathrm{I} .47(0.5 \mathrm{I}-4.22)$ & 0.001 & 78.3 & 0.473 & Random \\
\hline TNM stage & 5 & 387 & $0.70(0.46-1.08)$ & 0.108 & 47.2 & 0.111 & Fixed \\
\hline
\end{tabular}

Abbreviations: Random, random effects model; Fixed, fixed effects model; OR, odds ratio; $\mathrm{Cl}$, confidence interval.

In this analysis, five ${ }^{15,25,26,28,30}$ of eight, four ${ }^{25,26,28,31}$ of five, and three ${ }^{25,27,31}$ of four studies suggest that the expression of HSP27 correlated with the lymph node metastasis, TNM stage, and differentiation. However, the overall result showed no statistically significant association between HSP27 expression and these parameters. A previous meta-analysis ${ }^{22}$ reported that HSP27 expression was related to differentiation degree, lymphatic metastasis, and clinical stage in non-smallcell lung cancer. Unexpectedly, our results were the opposite. A possible reason is that the results are associated with different kinds of cancer. Without doubt, further high-quality studies are needed to provide more reliable evidence.

In our study, there is a significant heterogeneity in the analysis of HSP27 and several clinicopathological features.
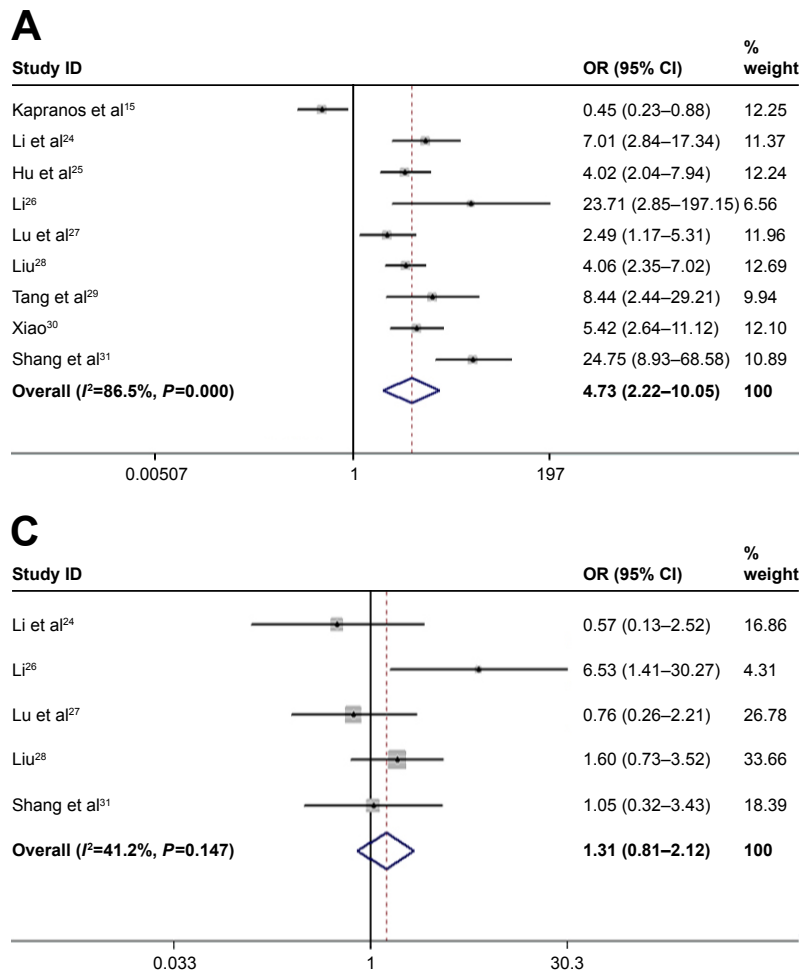

Although we conducted subgroup analysis and sensitivity analysis, the source of heterogeneity has not been fully explained. However, the heterogeneity may be produced in the following aspects. First, all the included studies tested the expression of HSP27 by IHC method, the quality of paraffin section, the antigen retrieval methods, and the use of primary antibody, and the dilutions of the antibodies were different, leading to a potential bias. Second, the cut-off defining a section with positive HSP27 expression is arbitrary, and the calculation error of positive results is unavoidable, which might also result in heterogeneity. In addition, all our findings, except for HSP27 expression, exhibited no publication bias. As eligible articles for meta-analysis were limited, and our review included only fully published studies, in order to

B

\begin{tabular}{|c|c|c|}
\hline Study ID & OR $(95 \% \mathrm{Cl})$ & $\begin{array}{l}\% \\
\text { weight }\end{array}$ \\
\hline Kapranos et al ${ }^{15}$ & $3.13(0.99-9.85)$ & 12.97 \\
\hline Li et $a^{24}$ & $0.38(0.09-1.63)$ & 10.77 \\
\hline Hu et $\mathrm{al}^{25}$ & $4.00(1.47-10.88)$ & 14.07 \\
\hline $\mathrm{Li}^{26}$ & $10.15(1.80-57.14)$ & 9.17 \\
\hline Lu et $a^{2^{27}}$ & $0.64(0.23-1.73)$ & 14.08 \\
\hline $\operatorname{Liu}^{28}$ & $0.69(0.30-1.59)$ & 15.31 \\
\hline $\mathrm{Xiao}^{30}$ & $1.23(0.36-4.12)$ & 12.49 \\
\hline Shang et $\mathrm{a}^{31}$ & $0.49(0.12-2.02)$ & 11.14 \\
\hline Overall $\left(l^{2}=67.1 \%, P=0.003\right)$ & $1.32(0.64-2.72)$ & 100 \\
\hline
\end{tabular}

\section{D}

\begin{tabular}{|c|c|c|}
\hline Study ID & OR $(95 \% \mathrm{Cl})$ & $\begin{array}{l}\% \\
\text { weight }\end{array}$ \\
\hline Kapranos et al ${ }^{15}$ & $0.59(0.24-1.43)$ & 21.43 \\
\hline Li et al ${ }^{24}$ & $0.70(0.20-2.51)$ & 9.51 \\
\hline Hu et $a^{25}$ & $1.35(0.48-3.74)$ & 10.43 \\
\hline Lu et $a^{27}$ & $1.15(0.44-3.00)$ & 13.08 \\
\hline $\operatorname{Liu}^{28}$ & $0.76(0.31-1.85)$ & 19.13 \\
\hline $\mathrm{Xiao}^{30}$ & $0.20(0.06-0.72)$ & 17.72 \\
\hline Shang et $\mathrm{a}^{31}$ & $0.79(0.22-2.93)$ & 8.69 \\
\hline Overall $\left(I^{2}=6.7 \%, P=0.377\right)$ & $0.73(0.50-1.08)$ & 100 \\
\hline
\end{tabular}

Figure 2 (Continued) 


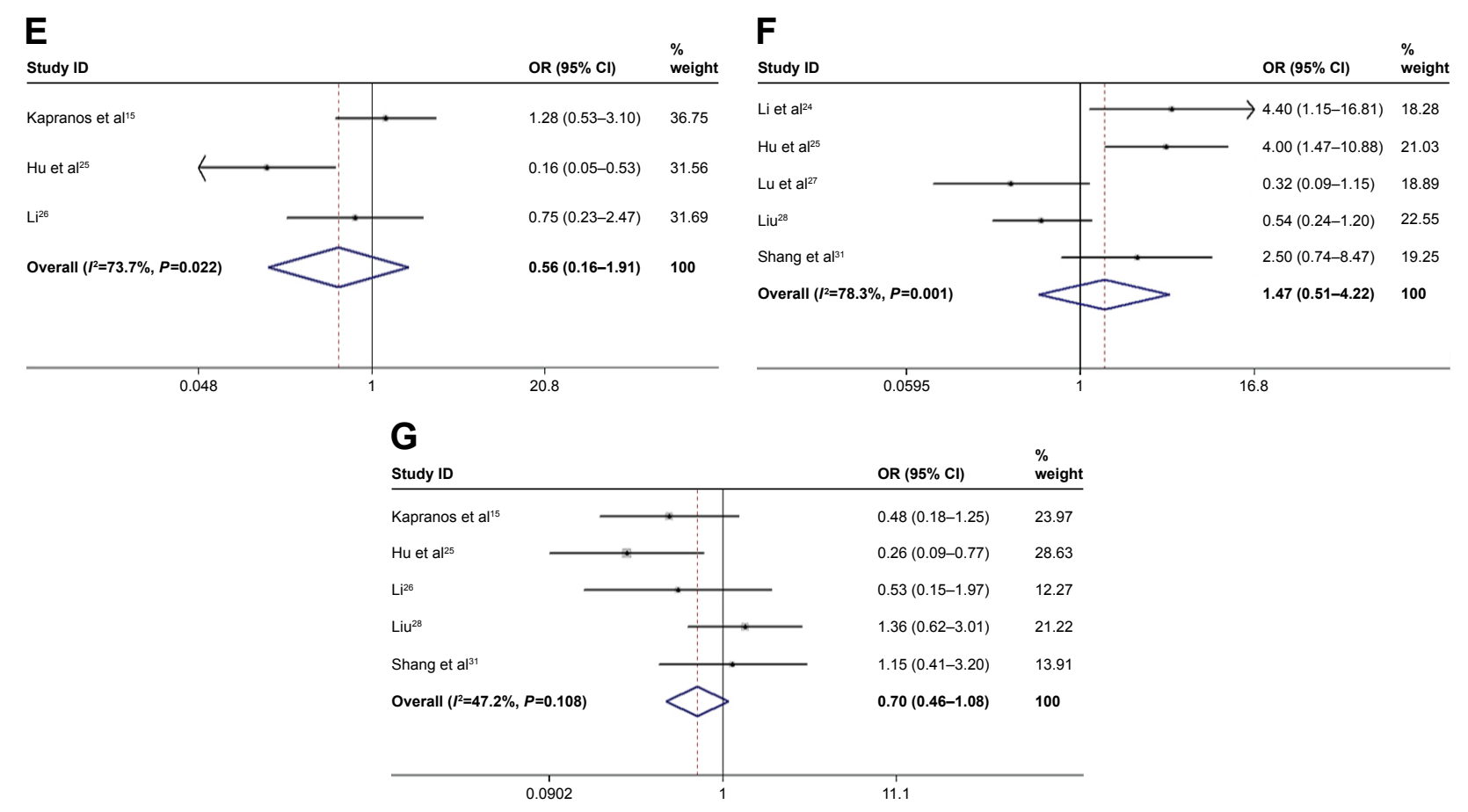

Figure 2 Forest plot of studies evaluating the relationship between HSP27 expression and clinicopathological features: (A) expression; (B) lymph node metastasis; (C) serosal invasion; (D) gender; (E) tumor size; (F) differentiation; (G) TNM stage.

Note: Weights are from random effects analysis.

Abbreviations: $\mathrm{OR}$, odds ratio; $\mathrm{Cl}$, confidence interval.
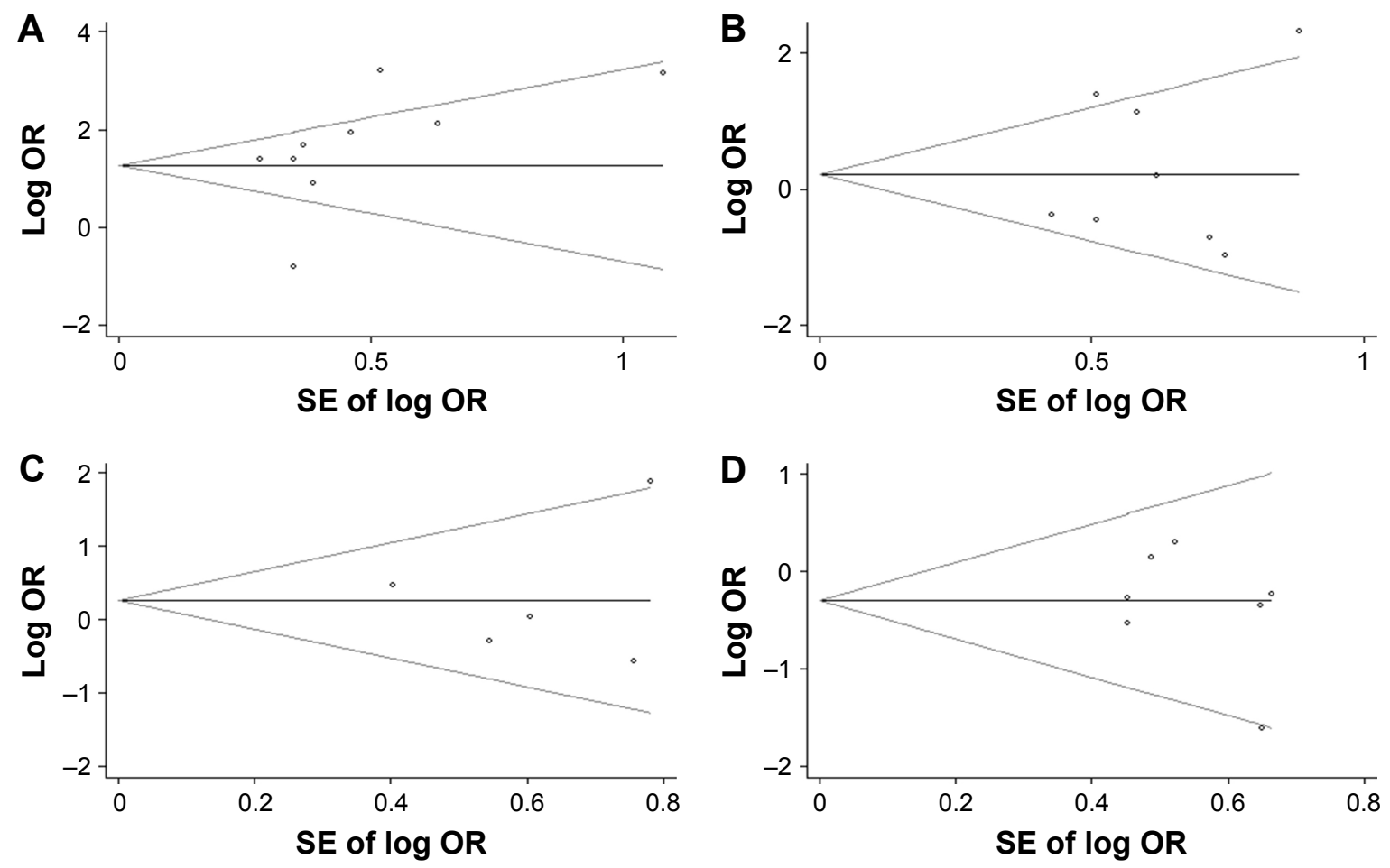

Figure 3 (Continued) 

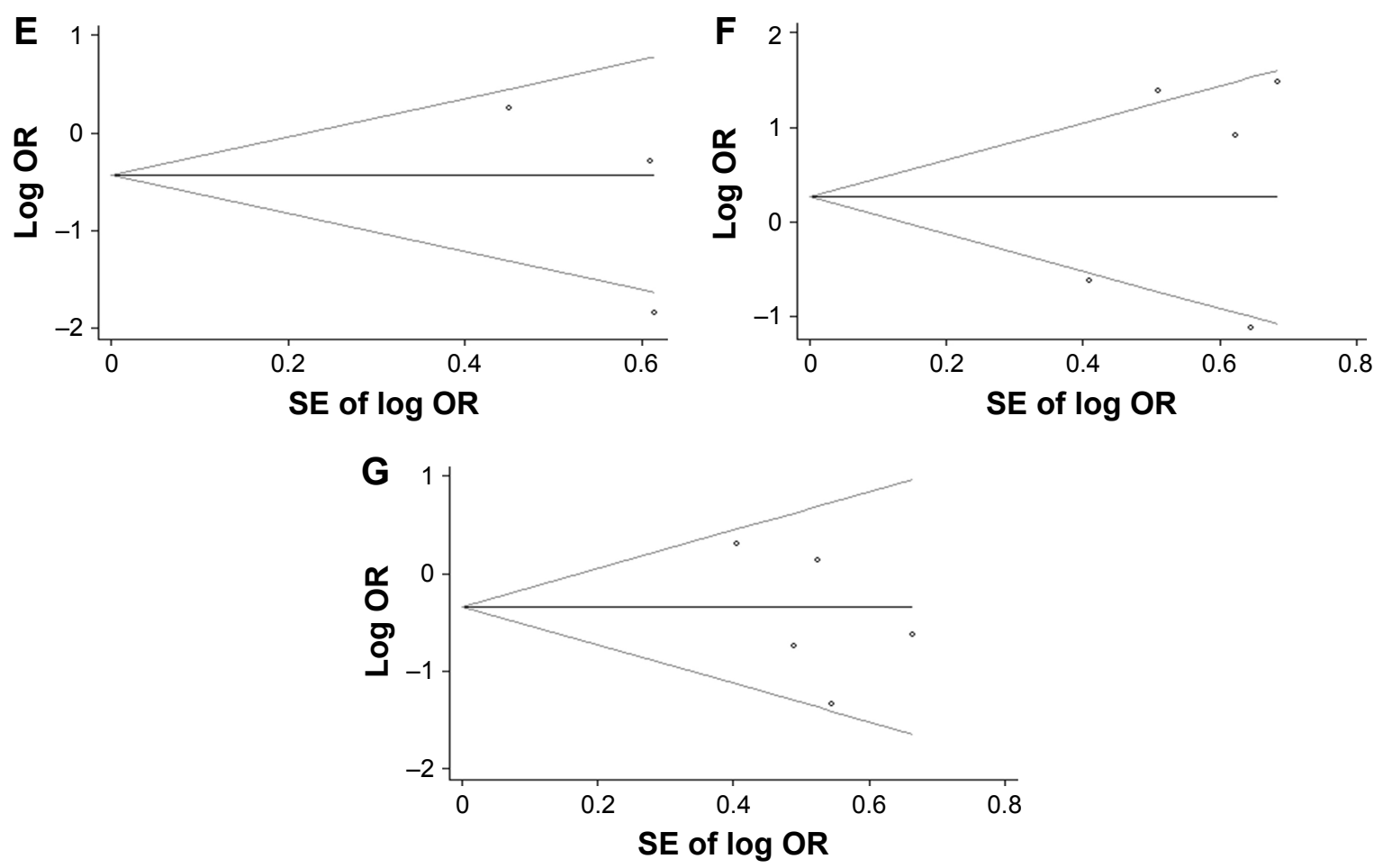

Figure 3 Begg's publication bias plot for HSP27 related studies: (A) expression; (B) lymph node metastasis; (C) serosal invasion; (D) gender; (E) tumor size; (F) differentiation; (G) TNM stage.

Abbreviations: SE, standard error; OR, odds ratio.

overcome the publication bias, more studies will be needed for further research.

\section{Limitations}

In this meta-analysis, several limitations should be considered: 1) the number of included studies was limited, therefore, the association of HSP27 expression with clinicopathological features still needs to be studied in a larger number of samples; 2) the sample sizes are relatively small; 3) most of the included studies were based on the population from China, so this may not generalize global populations.

Table 3 Subgroup analysis of expression, lymph node metastasis, tumor size, and differentiation

\begin{tabular}{|c|c|c|c|c|c|c|}
\hline Subgroups & No of studies & No of patients & Pooled OR $(95 \% \mathrm{Cl})$ & PHet & $P^{2}(\%)$ & $P$-value \\
\hline \multicolumn{7}{|l|}{ Expression } \\
\hline \multicolumn{7}{|l|}{ Sample size } \\
\hline$\leq 60$ & 4 & 187 & $12.15(6.12-24.13)$ & 0.260 & 25.2 & 0.000 \\
\hline$>60$ & 5 & 437 & $2.5 \mathrm{I}(1.05-6.0 \mathrm{I})$ & 0.000 & 88.2 & 0.039 \\
\hline \multicolumn{7}{|c|}{ Lymph node metastasis } \\
\hline \multicolumn{7}{|c|}{ Sample size } \\
\hline$\leq 60$ & 3 & 153 & $1.17(0.17-8.07)$ & 0.008 & 79.2 & 0.873 \\
\hline$>60$ & 5 & 437 & $1.42(0.66-3.08)$ & 0.023 & 64.6 & 0.370 \\
\hline \multicolumn{7}{|l|}{ Tumor size } \\
\hline \multicolumn{7}{|l|}{ Sample size } \\
\hline$\leq 60$ & I & 48 & $0.75(0.23-2.45)$ & - & - & 0.632 \\
\hline$>60$ & 2 & 161 & $0.47(0.06-3.66)$ & 0.006 & 86.8 & 0.473 \\
\hline \multicolumn{7}{|c|}{ Differentiation } \\
\hline \multicolumn{7}{|c|}{ Sample size } \\
\hline$\leq 60$ & 2 & 105 & $3.23(1.31-7.96)$ & 0.541 & 0.0 & 0.011 \\
\hline$>60$ & 3 & 261 & $0.90(0.2 \mid-3.91)$ & 0.002 & 84.2 & 0.892 \\
\hline
\end{tabular}

Abbreviations: $\mathrm{OR}$, odds ratio; $\mathrm{Cl}$, confidence interval; $\mathrm{n}$, number of sample size. 


\section{Conclusion}

The available evidence suggests that the incidence of gastric cancer is strongly dependent on the overexpression of HSP27. Clearly, further high-quality research studies with larger sample size are still needed to provide a more representative and convincing statistical analysis in the future.

\section{Disclosure}

The authors report no conflicts of interest in this work.

\section{References}

1. Fock KM. Review article: the epidemiology and prevention of gastric cancer. Aliment Pharmacol Ther. 2014;40(3):250-260.

2. Malvezzi M, Bonifazi M, Bertuccio P, et al. An age-period-cohort analysis of gastric cancer mortality from 1950 to 2007 in Europe. Ann Epidemiol. 2010;20:898-905.

3. Bertuccio P, Chatenoud L, Levi F, et al. Recent patterns in gastric cancer: a global overview. Int J Cancer. 2009;125(3):666-673.

4. Hendrick JP, Hartl FU. Molecular chaperone functions of heat shock proteins. Annu Rev Biochem. 1993;62:349-384.

5. Isomoto H, Oka M, Yano Y, et al. Expression of heat shock protein (Hsp) 70 and Hsp 40 in gastric cancer. Cancer Lett. 2003;198(2):219-228.

6. Partida RO, Torres J, Flores LL, et al. Polymorphisms in TNF and HSP-70 show a significant association with gastric cancer and duodenal ulcer. Int J Cancer. 2010;126(8):1861-1868.

7. Liu X, Ye L, Wang J, Fan D. Expression of heat shock protein 90 beta in human gastric cancer tissue and SGC7901/VCR of MDRtype gene gastric cancer cell line. Chin Med J (Engl). 1999;(12)112: $1133-1137$.

8. Giaginis C, Daskalopoulou SS, Vgenopoulou S, et al. Heat shock protein-27, -60 and -90 expression in gastric cancer: association with clinicopathological variables and patient survival. BMC Gastroenterol. 2009;9:14.

9. Zuo DS, Dai J, Bo AH, et al. Significance of expression of heat shock protein 90 alpha in human gastric cancer. World J Gastroenterol. 2003; 9(11):2616-2618.

10. Li XS, Xu Q, Fu XY, Luo WS. Heat shock protein 22 overexpression is associated with the progression and prognosis in gastric cancer. $J$ Cancer Res Clin Oncol. 2014;140(8):1305-1313.

11. Lindquist S, Craig EA. The heat-shock proteins. Annu Rev Genet. 1988; 22:631-677.

12. Gething MJ, Sambrook J. Protein folding in the cell. Nature. 1992; 355(6355):33-45.

13. Carver JA, Rekas A, Thorn DC, et al. Small heat-shock proteins and clusterin: intra- and extracellular molecular chaperones with a common mechanism of action and function? IUBMB Life. 2003;55(12): 661-668.

14. Ciocca DR, Oesterreich S, Chamness GC, et al. Biological and clinical implications of heat shock protein 27: a review. J Natl Cancer Inst. 1993; 85(19):1558-1570.

15. Kapranos N, Kominea A, Konstantinopoulos PA, et al. Expression of the 27-kDa heat shock protein (HSP27) in gastric carcinomas and adjacent normal, metaplastic, and dysplastic gastric mucosa, and its prognostic significance. J Cancer Res Clin Oncol. 2002;128(8):426-432.

16. Yu Z, Zhi J, Peng X, et al. Clinical significance of HSP27 expression in colorectal cancer. Mol Med Rep. 2010;3(6):953-958.

17. Joo M, Chi JG, Lee H. Expressions of HSP70 and HSP27 in hepatocellular carcinoma. J Korean Med Sci. 2005;20(5):829-834.

18. Małusecka E, Zborek A, Krzyzowska-Gruca S, et al. Expression of heat shock proteins HSP70 and HSP27 in primary non-small cell lung carcinomas. An immunohistochemical study. Anticancer Res. 2001;21(2A): 1015-1021.
19. Lomnytska MI, Becker S, Bodin I, et al. Differential expression of ANXA6, HSP27, PRDX2, NCF2, and TPM4 during uterine cervix carcinogenesis: diagnostic and prognostic value. Br J Cancer. 2011; 104(1):110-119.

20. Langdon SP, Rabiasz GJ, Hirst GL, et al. Expression of the heat shock protein HSP27 in human ovarian cancer. Clin Cancer Res. 1995;1(12): 1603-1609.

21. Ioachim E, Tsanou E, Briasoulis E, et al. Clinicopathological study of the expression of hsp27, pS2, cathepsin D and metallothionein in primary invasive breast cancer. Breast. 2003;12(2):111-119.

22. Li S, Zhang W, Fan J, et al. Clinicopathological and prognostic significance of heat shock protein 27 (HSP27) expression in non-small cell lung cancer: a systematic review and meta-analysis. Springerplus. 2016;5(1):1165.

23. Huang Q, Ye J, Huang Q, et al. Heat shock protein 27 is over-expressed in tumor tissues and increased in sera of patients with gastric adenocarcinoma. Clin Chem Lab Med. 2010;48(2):263-269.

24. Li GX, Li P, Yang ZM, et al. [Expression and clinical significance of HSP27 and Survivin in gastric carcinoma]. Shaanxi Medical Journal. 2010;39(1):93-96. Chinese.

25. Hu FL, He QY, Li XP, et al. [Expression and clinical significance of $\mathrm{P}$-cadherin and HSP27 proteins in gastric carcinoma]. Acta Universitatis Medicinalis Nanjing. 2015;1:26-30. Chinese.

26. Li GQ. [Expression and significance of heat shock protein 27 and p53 in gastric carcinoma]. Chin J Clin Gastroenterol. 2015;4:216-218. Chinese.

27. Lu AQ, Qin ZS, Lei SY. [Expression and significance of heat shock protein 27 in gastric carcinoma]. $J$ Snake. 2007;2:108-110. Chinese.

28. Liu B. [The role and potential mechanism of heat shock protein-27 in the metastasis and invasion of gastric cancer]. Thesis, The Fourth Military Medical University; 2014. Chinese.

29. Tang D, Tang SW, Luo ZW, et al. [The expression of heat shock protein27 in gastric cancer]. Tumor. 2009;3:272-275. Chinese.

30. Xiao Y. [CXCR1 relationship with clinical pathological features of gastric cancer and its related protein and the differences in protein HSP27 functional verification]. Thesis, Central South University; 2014. Chinese.

31. Shang JC, Qu YK, Liu WX. [The expression and clinical significance of HSP27, 70 and 90 in gastric cancer]. World Health Digest Medical Periodical. 2012;9(24):445-448. Chinese.

32. Ciocca DR, Calderwood SK. Heat shock proteins in cancers: diagnostic, prognostic, predictive, and treatment implications. Cell Stress Chaperones. 2005;10(2):86-103.

33. Creagh EM, Sheehan D, Cotter TG. Heat shock proteins-modulators of apoptosis in tumour cells. Leukemia. 2000;14(7):1161-1173.

34. Kim KK, Kim R, Kim SH. Crystal structure of a small heat-shock protein. Nature. 1998;394(6693):595-599.

35. Stetler RA, Gao Y, Signore AP, et al. HSP27: mechanisms of cellular protection against neuronal injury. Curr Mol Med. 2009;9(7):863-872.

36. Bruey JM, Ducasse C, Bonniaud P, et al. Hsp27 negatively regulates cell death by interacting with cytochrome c. Nat Cell Biol. 2000;2(9): 645-652.

37. Charette SJ, Lavoie JN, Lambert H, et al. Inhibition of daxx-mediated apoptosis by heat shock protein 27. Mol Cell Biol. 2000;20(20): 7602-7612.

38. Konishi H, Matsuzaki H, Tanaka M, et al. Activation of protein kinase B (akt/rac-protein kinase) by cellular stress and its association with heat shock protein Hsp27. FEBS Lett. 1997;410(2-3):493-498.

39. Song H, Ethier SP, Dziubinski ML, et al. Stat3 modulates heat shock $27 \mathrm{kDa}$ protein expression in breast epithelial cells. Biochem Biophys Res Commun. 2004;314(1):143-150.

40. Guo K, Kang NX, Li Y, et al. regulation of HSP27 on NF-kappaB pathway activation may be involved in metastatic hepatocellular carcinoma cell apoptosis. BMC Cancer. 2009;9:100. 
OncoTargets and Therapy

\section{Publish your work in this journal}

OncoTargets and Therapy is an international, peer-reviewed, open access journal focusing on the pathological basis of all cancers, potential targets for therapy and treatment protocols employed to improve the management of cancer patients. The journal also focuses on the impact of management programs and new therapeutic agents and protocols on

patient perspectives such as quality of life, adherence and satisfaction. The manuscript management system is completely online and includes a very quick and fair peer-review system, which is all easy to use. Visit http://www.dovepress.com/testimonials.php to read real quotes from published authors.

Submit your manuscript here: http://www.dovepress.com/oncotargets-and-therapy-journal 